\title{
Involvement of Bone Morphogenetic Proteins (BMPs) in Ovarian Function and Infertility
}

\author{
A.A. Vireque ${ }^{*}, 1$, R.M. Reis ${ }^{1}$, A.A.M. Rosa e Silva ${ }^{2}$, L.O.T. Resende ${ }^{1}$, E.M. Ferreira ${ }^{1}$, \\ A.C.J.S. Rosa e Silva ${ }^{1}$ and R.A. Ferriani ${ }^{1}$ \\ ${ }^{I}$ Department of Gynecology and Obstetrics, Faculty of Medicine of Ribeirão Preto, University of São Paulo, Brazil \\ ${ }^{2}$ Department of Physiological Sciences, University of Brasilia, Brazil
}

\begin{abstract}
Advances in assisted reproduction techniques and the treatment of diseases known to be correlated with infertility such as polycystic ovary syndrome and premature ovarian failure require a better understanding of ovarian physiology. Despite the enormous quantity of information produced over the last two decades, the mechanisms controlling follicular development are not fully understood. Ovarian function is regulated by interactions between gonadotropins, follicle stimulating hormone, luteinizing hormone and local ovarian factors such as inhibins, activins, bone morphogenetic protein-15 (BMP-15) and growth differentiation factor-9 (GDF-9), all members of the transformation and growth factor- $\beta$ (TGF- $\beta$ ) superfamily. There is evidence of a functional ovarian BMP system with countless genes involved in normal follicular development and in fertility. The present review summarizes the ligands of the TGF- $\beta$ superfamily, their receptors and signaling pathways and discusses the ovarian functions of the BMPs secreted by the oocytes as critical regulators of fertility.
\end{abstract}

\section{INTRODUCTION}

The progress of the ovarian follicle through the successive stages of folliculogenesis depends on an effective bidirectional communication pathway between the oocyte and the somatic follicular cells and also requires endocrine signals, mainly gonadotropins and steroids which act on the receptors on the two cell types and interact with local autocrine/paracrine signaling pathways. Several growth factors, including the members of the TGF- $\beta$ superfamily, are expressed by the oocyte and by follicular cells in specific stages of development and function as intraovarian regulatory molecules involved in follicular recruitment, proliferation/atresia of granulosa and theca cells, steroidogenesis, oocyte maturation, ovulation, and luteinization $[1,2]$. Normal follicular development depends on the coordination between the processes of proliferation/differentiation of somatic cells and of growth/maturation of the oocyte, and the oocyte-granulosa cell signaling is of critical importance for insuring this coordination, promoting integrated cell functions $[3,4]$. Intercellular communication occurs via transzonal cytoplasmic processes and paracrine mediators. Particularly important among them are the stem cell factor, also known as kit-ligand (KL), and bone morphogenetic proteins (BMPs), the GDF-9 and BMP-15 or GDF9B [4]. Mutations that inactivate the GDF-9 and BMP-15 genes are associated with premature ovarian failure and infertility in sheep and in women, indicating the fundamental participation of these growth factors in the regulation of folliculogenesis and ovulation $[5,6]$. In addition, a GDF-9/BMP-15-KL feedback loop has been described as an important signaling mechanism on

*Address correspondence to this author at the Faculty of Medicine of Ribeirão Preto - University of São Paulo, Av Bandeirantes, 3900. Zip Code 14049-900, Ribeirão Preto, SP, Brazil; Tel: 5516 3602-2818; Fax: 5516 3602-2231;

E-mail: raferria@fmrp.usp.br or alessandra_vireque@yahoo.com.br the oocyte-granulosa cell interface, as well as a mechanism of coordination of follicular development $[1,7,8]$.

\section{THE TGF- $\beta$ SUPERFAMILY}

The extracellular signaling molecules of the TGF- $\beta$ superfamily comprise approximately 30 structurally related and functionally distinct proteins which in mammals include three TGF- $\beta$ isoforms (TGF- $\beta 1,2,3)$, anti-müllerian hormone $(\mathrm{AMH})$, two inhibins $(\mathrm{A}$ and $\mathrm{B})$, three activins $(\mathrm{A}, \mathrm{B}, \mathrm{AB})$, 20 BMPs (BMP-1-BMP-20), and nine growth and differentiation factors (GDF-1-GDF-9) [9]. Collectively, the ligands of the TGF- $\beta$ superfamily have regulatory functions in a wide variety of tissues, with a well-documented participation in processes such as the induction of the embryonic mesoderm, differentiation of the genital duct, ovarian folliculogenesis, and other physiological processes [10,11]. Among the factors expressed in the ovary are GDF-9, GDF-9B (BMP-15), inhibins, activins, TGF- $\beta$, BMPs $2,4,6$, 7, and AMH [2].

\section{THE OOCYTE GROWTH FACTORS: THE BMPS}

BMPs are multifunctional cytokines that can regulate cell proliferation/differentiation, deposition of the extracellular matrix, and apoptosis [12]. Among the 20 known BMPs, eight are implicated in the formation and/or function of mammalian germ cells and in ovarian formation/function (BMP-2, BMP-4, BMP-6, BMP-7, BMP-15 and GDF-9) [13-16], with GDF-9, BMP-15 and BMP-6 being selectively expressed by the oocyte in different species in the early stages of folliculogenesis [2, 17-19]. BMPs are synthesized and secreted as prepropeptides and are proteolytically cleaved to form activated disulfide-linked dimers, most of them being homodimers. However, the gene products of BMP-15 and GDF-9 can form heterodimers [20]. 


\section{OVARIAN FUNCTIONS OF BMPS SECRETED BY OOCYTE}

The expression and bioactivity of oocyte growth factors have been investigated in studies mainly focusing on murine culture systems and have demonstrated that the oocyte regulates various parameters of follicular cell function in vitro, particularly by stimulating mitotic activity and estradiol secretion and inhibiting progesterone synthesis [21, 22]. These data have also been reported for swine, sheep, bovine, nonhuman primate and human ovaries [13, 23-28]. Deletion of the gdf9 gene causes infertility with blockade of folliculogenesis in the primary stage in mice [14] and results in down-regulation of mRNA expression for activin $\mathrm{B} \beta$, follistatin and cyclooxygenase 2 , as well as a significant upregulation of $\mathrm{KL}$ expression [3], with the development of follicles with atypical granulosa cells (GC) and without the theca cell (TC) layer. Thus, GDF-9 can bind to the receptors of granulosa cells and regulate the expression of various gene products [29]. During terminal follicle maturation, GDF-9 performs important functions in order to trigger the mechanisms associated with ovulation, such as: 1) maintaining the structural integrity of the preovulatory follicle, inducing hyaluronan synthetase 2 and pentraxin 3 and suppressing the plasminogen activator urokinase; 2) stimulating prostaglandin and progesterone synthesis; 3) suppressing early luteinization of cumulus GC, thus inhibiting the synthesis of LHR mRNA and the expansion of the cumulus [30]. BMP15 stimulates cell proliferation with an FSH-independent mitogenic effect in primary rat GC cultures [18, 31]. It also suppresses the expression of $\mathrm{FSH}$ receptors and stimulates KL expression [32]. The biological effects of BMP-6 on GC differ from those of other BMPs. BMP-6 has no mitogenic effect on GC [33] and inhibits the production of P4 induced by forskolin, and the expression of StAR and P450scc mRNA [34]. The mechanism by which BMP-6 inhibits the action of FSH probably involves down-regulation of adenylate cyclase activity, in contrast to BMP-15, which inhibits the basal expression of FSH receptors.

\section{RECEPTOR AND INTRACELLULAR SIGNALING OF BMPs}

The members of the TGF- $\beta$ superfamily bind to the serine/threonine kinase membrane receptors and activate the Smad transcription factors $[35,36]$. In the human genome, the serine/threonine kinase receptor family comprises 12 members, five of them being type II receptors: type II BMP receptor (BMPRII), type II anti-müllerian hormone receptor (AMHRII), type II TGF- $\beta$ receptor, and type II activin receptors (ATCRIIA and ATCRIIB). There are also seven type I receptors referred to as activin kinase-like (ALK) receptors [37]. Both receptor types consist of approximately 500 amino acids and present an aminoterminal extracellular domain with 10 or more cysteines, a transmembrane region, and a carboxy terminal serine/threonine kinase domain. The ligands activate two main intracellular signaling pathways characterized by the activation of two different Smad protein groups: Smad 1/5/8 and Smad 2/3 (Fig. 1) [38, 39]. BMPs, like other ligands of the TGF- $\beta$ family, act on serine/threonine kinase receptors [12], and signal transduction requires the formation of a hetero-oligomeric complex with BMP receptors (BMPRs) of types II and IA or IB (ALK)
$[12,40]$. BMPR-II has autophosphorylation activity and is responsible for the activation of the type I receptor after the complex is formed. After receptor activation, a signaling cascade is started, involving the phosphorylation, heterodimerization and migration of Smad proteins to the nucleus [40]. The activated Smad complexes translocated to the nucleus, together with other nuclear co-factors, regulate the transcription of target genes [11] (Fig. 1). The transcription factor-Smad interaction determines the precise response to the ligand in different cell types and in cooperation with other signaling pathways [41]. GDF-9 interacts with the BMPRII and ALK5 receptors and activates the Smad 2/3 pathway, while BMP-15 activates the Smad $1 / 5 / 8$ pathway by interacting with the BMPRII and ALK6 receptors, as observed in rat GC [31]. The activation of distinct signaling pathways by homodimers of GDF-9 and BMP-15 may be associated with specific functions of these BMPs in follicular development. However, GDF-9 and BMP-15 can form homo- or heterodimers [20,42] and the latter can activate, like GDF-9, a hybrid of the two signaling pathways [33]. The three types of BMP receptors are expressed in the different types of ovarian cells, including the oocyte, GC, TC, and epithelial and endothelial ovarian cells of rats, sows, sheep and women [15, 28, 43-45]. BMPRs have also been observed in the fetal swine ovary, indicating their involvement in the formation of ovarian follicles [44]. The presence of BMP receptors and the ability of these factors to modulate steroidogenesis are indicative of a functional intraovarian BMP system.

\section{REGULATION OF BMP EXPRESSION IN THE OVARY}

It is still unclear which factor is responsible for the activation or regulation of BMP expression in the ovary. Two factors pointed out as regulatory of BMP activity are follistatin and KL. Follistatin can specifically bind to BMPs and attenuate changes induced by these proteins in bovine and rat GC $[16,46]$. BMP-15 and GDF-9 respectively stimulate and inhibit the expression of KL and KL inhibits the expression of BMP-15 [7, 8]. Thus, follistatin and KL may represent two potential regulatory mechanisms for the control of BMP activity in the ovary. However, these interactions and others still need to be clarified.

\section{BMPs AND INFERTILITY}

The recent interest in BMPs derives from observations that correlate induced or spontaneous genetic mutations in members of the BMP family with impairment of ovarian development and ovulation $[6,14,47,48]$. Spontaneous mutations in the ovine and murine BMP-15 (FecX) genes and in the ovine GDF-9 $(\mathrm{Fe} G \mathrm{C})$ gene may drastically alter fertility and ovulatory rate in this mammalian species. Deletion of the bmp 15 or gdf9 genes (sheep, mice) or immunization against BMP-15 (sheep) results in infertile animals [49, 50]. Infertility is due to delayed follicular development and histological examination reveals large oocytes, absent or abnormal granulosa proliferation, and faulty thecal recruitment (GDF-9-knockout mice) [14, 51]. Inverdale and Hanna sheep, by presenting BMP-15-inactivating mutations, represent an interesting model for the understanding of the functions of this protein in the control of folliculogenesis. 


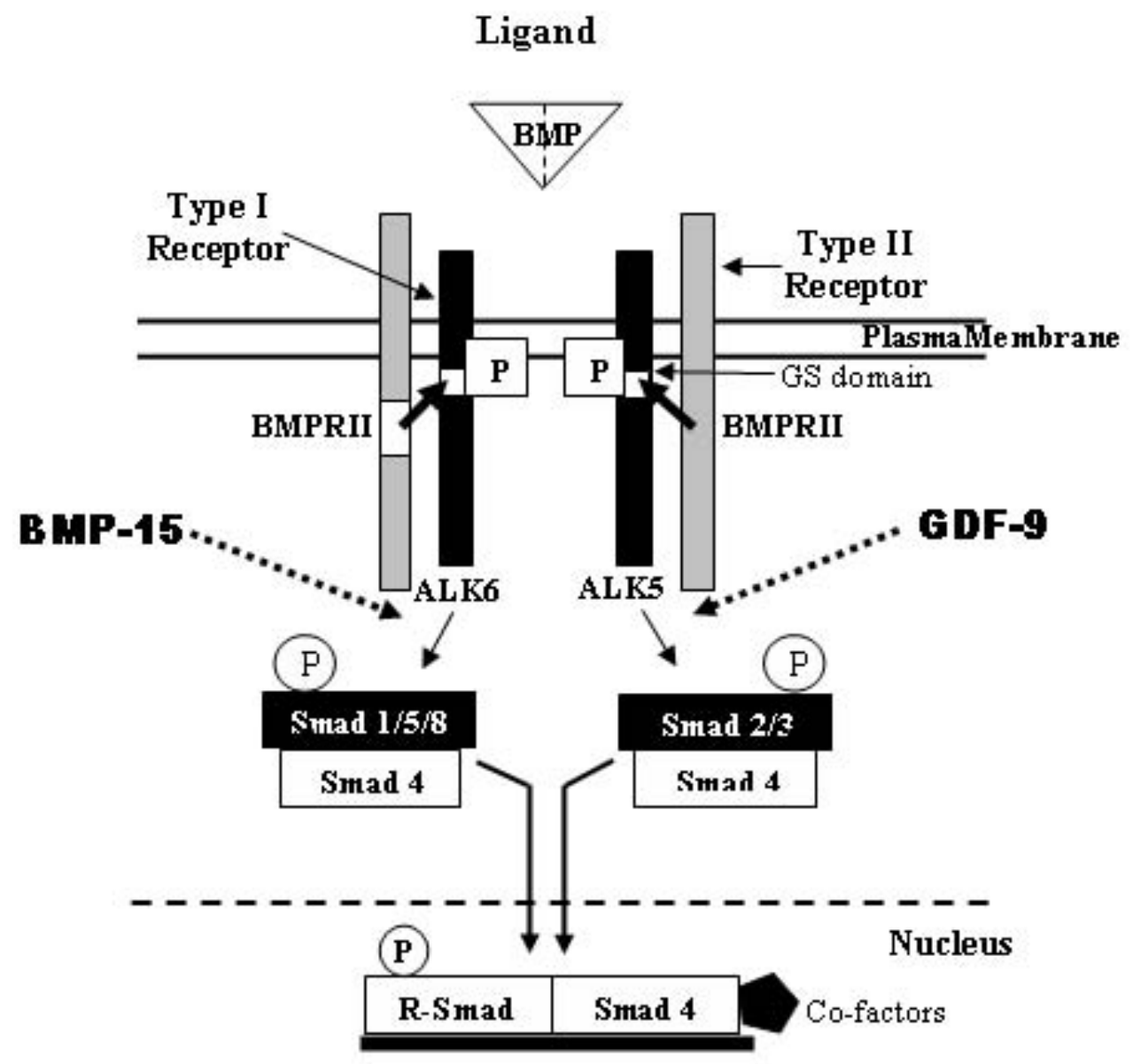

Target gene

Fig. (1). Receptors and signaling pathways of BMP-15 and GDF-9. The GDF-9 or BMP-15 dimers bind to specific serine-threonine kinase type I and type II receptors and the formation of the tetramer ( 2 type 1 and 2 type II receptors for each ligand) permits the phosphorylation of the type I receptor by the type II receptor in the glycine-serine (GS) domain, resulting in the formation of the signal transduction complex. Type I ALK5 and ALK6 receptors respectively recognize and phosphorylate R-Smads 2/3 and 1/5/8. The phosphorylated R-Smads form complexes with Smad-4 (Co-Smads) and are translocated to the nucleus, where they interact with specific DNA motifs. The effective binding to the target gene is modulated by various nuclear cofactors that co-activate or co-repress transcription.

Mutation in homozygosis $\left(\mathrm{Fec} \mathrm{X}^{\mathrm{I}} / \mathrm{Fec} \mathrm{X}^{\mathrm{I}}\right)$ causes infertility with blockade of folliculogenesis in the primary stage [51], while mutation in heterozygosis $\left(\mathrm{FecX}^{\mathrm{I}} / \mathrm{Fec} \mathrm{X}^{+}\right)$causes an increase in ovulatory rate and multiple births $[6,52]$. Similarly, spontaneous mutations in the gdf 9 gene in Belclare and Cambridge sheep cause a dose-dependent increase in ovulatory rates [49]. In the Booroola race, spontaneous mutations that inactivate the genes coding for BMP receptors, such as BMPR-IB $(F e c B)$, also cause similar changes in ovulatory rate $[45,53]$. It has been suggested that the reduced availability of BMP-15 in heterozygous sheep may stimulate follicular development by increasing sensitivity to FSH, since in vitro studies indicate that BMP- 15 inhibits the expression of FSH receptors [19]. In fact, the characteristics of early follicular development are larger oocytes and granulosa cells more responsive to FSH and with a lower proliferative activity than normal GC $[52,53]$. In this case, the ovary produces a large number of smaller and more estrogenic follicles that escape endocrine control, most of them progressing to ovulation. Some authors have investigated in human ovaries the correlation between mutations in the $g d f 9$ and bmp15 genes and diseases such as premature ovarian failure (POF) and polycystic ovary syndrome (POS) $[47,48,54]$. The detection of GDF-9 and BMP-15 mRNA in normal human oocytes indicates that these factors may play a fundamental role in folliculogenesis and fertility in women [55]. POF occurring before 40 years of age is a heterogeneous condition caused by autoimmune or genetic changes and in most cases its etiology is unknown [56]. This condition may mean that the follicular cohort suffers atresia at accelerated rates or that the follicles do not respond to gonadotropin stimulation [54]. Evaluation of bmp15 and $g d f 9$ in different populations of women with POF has suggested that these changes rarely occur in this disease [54]. Mutational analyses of these genes in a group of women with a clinical diagnosis of POF have not reached conclusive results but indicate that this is a plausible explanation for POF. However, discordant results have been obtained for different populations and ethnic groups and some authors have suggested that mutations in the $g d f 9$ gene associated with POF present a spectrum that varies ac- 
cording to the population, rather than representing a single mutation shared by all populations [57]. Polycystic ovary syndrome (POS) is one of the most common causes of anovulation, infertility and menstrual irregularity in women, affecting 5 to $10 \%$ of women of reproductive age. POS has been defined as a syndrome involving polycystic ovaries, hyperandrogenism, and chronic anovulation, with the exclusion of specific diseases of the ovaries, adrenal glands and pituitary [58]. There is evidence indicating that the mechanism of POS involves ovarian dysfunction [59]. In POS, the ovaries contain double the normal number of growing follicles, supporting this hypothesis. This finding is particularly significant by suggesting that all steps in the folliculogenesis process can be aberrant in this syndrome. In addition, there is evidence that, in POS, follicular growth and development stops when the follicles reach 4 to $7 \mathrm{~mm}$, causing an accumulation of large numbers of small follicles in the tunica albuginea. The interstitial theca cells associated with follicle development exhibit high levels of androgen biosynthesis and also support the role of the ovaries in POS [60]. This evidence raises the hypothesis that abnormal folliculogenesis occurs in POS [55]. Due to altered folliculogenesis and cyst formation in this syndrome, the expression of GDF-9 and BMP-15 was assessed in women with POS and in women with polycystic ovaries during follicular development. The mRNA levels of GDF-9, but not of BMP-15, were found to be reduced in this group of women during the phase of differentiation and growth [55]. In assisted reproduction techniques the quality of the oocytes obtained with controlled ovarian hyperstimulation varies widely. Only half of these fertilized oocytes complete preimplantation development and few of them do implant. Some studies have demonstrated that changes in the expression of genes such as $g d f 9$ and bmp 15 in the oocytes or in pentraxin 3 in cumulus cells can be monitored for an appropriate selection of the oocyte to be fertilized [61]. These observations illustrate the importance of BMP-15 as a regulator of fertility and indicate that the BMPs secreted by the oocyte are the apex of the regulatory mechanisms associated with folliculogenesis. However, fertility and the development of healthy follicles and oocytes depend on various paracrine and endocrine factors in addition to BMPs. The IGF/IGFBP system, the fibroblast growth factors, epidermal growth factor/TGF- $\alpha$, the endothelial growth factors, interleukins and members of the TGF- $\beta$ superfamily such as activins, follistatins, inhibins and antimüllerian hormone are among several other intraovarian peptides involved in the control of folliculogenesis.

\section{CONCLUSIONS}

The severe consequences of mutations and deletions in the $g d f 9$ and bmp 15 genes for the number of dominant follicles and the ovulatory rate of mice and sheep demonstrate the fundamental importance for ovarian function of these proteins secreted by the oocyte. However, little information is available about the actions of these factors on human infertility. In view of the impact of GDF-9 and BMP-15 on reproduction in animal models, it is clear that the GDF9/BMP-15 system represents an important focal approach to the treatment of infertile women. Studies defining the precise involvement of these factors in human ovarian physiology/physiopathology are needed for the advancement of basic science and for the potential application of the knowledge obtained to clinical biotechnology involving the ovarian BMP system.

\section{REFERENCES}

[1] Hunter MG, Brankin V, Quinn RL, Ferguson EM, Edwards SA, Ashworth CJ. Oocyte-somatic cell-endocrine interactions in pigs. Domest Anim Endocrinol 2005; 29: 371-84.

[2] Knight PG, Glister C. Local roles of TGF-beta superfamily members in the control of ovarian follicle development. Anim Reprod Sci 2003; 78: 165-83.

[3] Eppig JJ, Wigglesworth K, Pendola FL. The mammalian oocyte orchestrates the rate of ovarian follicular development. Proc Natl Acad Sci USA 2002; 99: 2890-4.

[4] Thomas FH, Vanderhyden BC. Oocyte-granulosa cell interactions during mouse follicular development: regulation of kit ligand expression and its role in oocyte growth. Reprod Biol Endocrinol 2006; 4: 19.

[5] Di Pasquale E, Beck-Peccoz P, Persani L. Hypergonadotropic ovarian failure associated with an inherited mutation of human bone morphogenetic protein-15 (BMP15) gene. Am J Hum Genet 2004; 75: 106-11.

[6] Galloway SM, McNatty KP, Cambridge LM, et al. Mutations in an oocyte-derived growth factor gene (BMP15) cause increased ovulation rate and infertility in a dosage-sensitive manner. Nat Genet 2000; $25: 279-83$.

[7] Joyce IM, Clark AT, Pendola FL, Eppig JJ. Comparison of recombinant growth differentiation factor-9 and oocyte regulation of KIT ligand messenger ribonucleic acid expression in mouse ovarian follicles. Biol Reprod 2000; 63: 1669-75.

[8] Otsuka F, Shimasaki S. A negative feedback system between oocyte bone morphogenetic protein 15 and granulosa cell kit ligand: its role in regulating granulosa cell mitosis. Proc Natl Acad Sci USA 2002; 99: 8060-5.

[9] Massague J, Wotton D. Transcriptional control by the TGFbeta/Smad signaling system. EMBO J 2000; 19: 1745-54.

[10] Chang H, Brown CW, Matzuk MM. Genetic analysis of the mammalian transforming growth factor-beta superfamily. Endocr Rev 2002; 23: 787-823.

[11] Mazerbourg S, Hsueh AJ. Genomic analyses facilitate identification of receptors and signalling pathways for growth differentiation factor 9 and related orphan bone morphogenetic protein/growth differentiation factor ligands. Hum Reprod Update 2006; 12: 373-83.

[12] Massague J, Chen YG. Controlling TGF-beta signaling. Genes Dev 2000; 14: 627-44.

[13] Bodensteiner KJ, Clay CM, Moeller CL, Sawyer HR. Molecular cloning of the ovine Growth/Differentiation factor-9 gene and expression of growth/differentiation factor-9 in ovine and bovine ovaries. Biol Reprod 1999; 60: 381-6.

[14] Dong J, Albertini DF, Nishimori K, Kumar TR, Lu N, Matzuk MM. Growth differentiation factor-9 is required during early ovarian folliculogenesis. Nature 1996; 383: 531-5.

[15] Erickson GF, Shimasaki S. The spatiotemporal expression pattern of the bone morphogenetic protein family in rat ovary cell types during the estrous cycle. Reprod Biol Endocrinol 2003; 1: 9 .

[16] Glister C, Kemp CF, Knight PG. Bone morphogenetic protein (BMP) ligands and receptors in bovine ovarian follicle cells: actions of BMP-4, -6 and -7 on granulosa cells and differential modulation of Smad-1 phosphorylation by follistatin. Reproduction 2004; 127: 239-54.

[17] Aaltonen J, Laitinen MP, Vuojolainen K, et al. Human growth differentiation factor 9 (GDF-9) and its novel homolog GDF-9B are expressed in oocytes during early folliculogenesis. J Clin Endocrinol Metab 1999; 84: 2744-50.

[18] Otsuka F, Yao Z, Lee T, Yamamoto S, Erickson GF, Shimasaki S Bone morphogenetic protein-15. Identification of target cells and biological functions. J Biol Chem 2000; 275: 39523-8.

[19] Otsuka F, Yamamoto S, Erickson GF, Shimasaki S. Bone morphogenetic protein-15 inhibits follicle-stimulating hormone (FSH) action by suppressing FSH receptor expression. J Biol Chem 2001; 276: 11387-92.

[20] Vitt UA, Mazerbourg S, Klein C, Hsueh AJ. Bone morphogenetic protein receptor type II is a receptor for growth differentiation factor-9. Biol Reprod 2002; 67: 473-80.

[21] Vanderhyden BC, Cohen JN, Morley P. Mouse oocytes regulate granulosa cell steroidogenesis. Endocrinology 1993; 133: 423-6. 
[22] Vanderhyden BC, Macdonald EA. Mouse oocytes regulate granulosa cell steroidogenesis throughout follicular development. Biol Reprod 1998; 59: 1296-301.

[23] Brankin V, Quinn RL, Webb R, Hunter MG. Evidence for a functional bone morphogenetic protein (BMP) system in the porcine ovary. Domest Anim Endocrinol 2005; 28: 367-79.

[24] Brankin V, Mitchell MR, Webb B, Hunter MG. Paracrine effects of oocyte secreted factors and stem cell factor on porcine granulosa and theca cells in vitro. Reprod Biol Endocrinol 2003; 1: 55.

[25] Glister C, Tannetta DS, Groome NP, Knight PG. Interactions between follicle-stimulating hormone and growth factors in modulating secretion of steroids and inhibin-related peptides by nonluteinized bovine granulosa cells. Biol Reprod 2001; 65: 1020-8.

[26] Jaatinen R, Bondestam J, Raivio T, et al. Activation of the bone morphogenetic protein signaling pathway induces inhibin beta(B)subunit mRNA and secreted inhibin B levels in cultured human granulosa-luteal cells. J Clin Endocrinol Metab 2002; 87: 1254-61.

[27] Duffy DM. Growth differentiation factor-9 is expressed by the primate follicle throughout the periovulatory interval. Biol Reprod 2003; 69: 725-32.

[28] Souza CJ, Campbell BK, McNeilly AS, Baird DT. Effect of bone morphogenetic protein 2 (BMP2) on oestradiol and inhibin A production by sheep granulosa cells, and localization of BMP receptors in the ovary by immunohistochemistry. Reproduction 2002; 123: 363-9.

[29] Elvin JA, Clark AT, Wang P, Wolfman NM, Matzuk MM. Paracrine actions of growth differentiation factor-9 in the mammalian ovary. Mol Endocrinol 1999; 13: 1035-48.

[30] Matzuk MM, Burns KH, Viveiros MM, Eppig JJ. Intercellular communication in the mammalian ovary: oocytes carry the conversation. Science 2002; 296:2178-80.

[31] Moore RK, Otsuka F, Shimasaki S. Molecular basis of bone morphogenetic protein-15 signaling in granulosa cells. J Biol Chem 2003; 278: 304-10.

[32] Nuttinck F, Peynot N, Humblot P, Massip A, Dessy F, Flechon JE. Comparative immunohistochemical distribution of connexin 37 and connexin 43 throughout folliculogenesis in the bovine ovary. Mol Reprod Dev 2000; 57: 60-6.

[33] Gilchrist RB, Ritter LJ, Myllymaa S, et al. Molecular basis of oocyte-paracrine signalling that promotes granulosa cell proliferation. J Cell Sci 2006; 119: 3811-21.

[34] Otsuka F, Moore RK, Shimasaki S. Biological function and cellular mechanism of bone morphogenetic protein-6 in the ovary. J Biol Chem 2001; 276: 32889-95.

[35] Kawabata M, Imamura T, Miyazono K. Signal transduction by bone morphogenetic proteins. Cytokine Growth Factor Rev 1998; 9: 49-61.

[36] Massague J. TGF-beta signal transduction. Annu Rev Biochem 1998; 67: 753-91

[37] ten Dijke P, Ichijo H, Franzen P, et al. Activin receptor-like kinases: a novel subclass of cell-surface receptors with predicted serine/threonine kinase activity. Oncogene 1993; 8: 2879-87.

[38] Liu F, Ventura F, Doody J, Massague J. Human type II receptor for bone morphogenic proteins (BMPs): extension of the two-kinase receptor model to the BMPs. Mol Cell Biol 1995; 15: 3479-86.

[39] Nakao A, Imamura T, Souchelnytskyi S, et al. TGF-beta receptormediated signalling through Smad2, Smad3 and Smad4. EMBO J 1997; 16: 5353-62.

[40] Miyazono K, Kusanagi K, Inoue H. Divergence and convergence of TGF-beta/BMP signaling. J Cell Physiol 2001; 187: 265-76.

[41] Shi Y, Massague J. Mechanisms of TGF-beta signaling from cell membrane to the nucleus. Cell 2003; 113: 685-700.

[42] McPherron AC, Lee SJ. GDF-3 and GDF-9: two new members of the transforming growth factor-beta superfamily containing a novel pattern of cysteines. J Biol Chem 1993; 268: 3444-9.
[43] Kaivo-Oja N, Mottershead DG, Mazerbourg S, et al. Adenoviral gene transfer allows Smad-responsive gene promoter analyses and delineation of type I receptor usage of transforming growth factorbeta family ligands in cultured human granulosa luteal cells. J Clin Endocrinol Metab 2005; 90: 271-8.

[44] Quinn RL, Shuttleworth G, Hunter MG. Immunohistochemical localization of the bone morphogenetic protein receptors in the porcine ovary. J Anat 2004; 205: 15-23.

[45] Wilson T, Wu XY, Juengel JL, et al. Highly prolific Booroola sheep have a mutation in the intracellular kinase domain of bone morphogenetic protein IB receptor (ALK-6) that is expressed in both oocytes and granulosa cells. Biol Reprod 2001; 64: 1225-35.

[46] Otsuka F, Moore RK, Iemura S, Ueno N, Shimasaki S. Follistatin inhibits the function of the oocyte-derived factor BMP-15. Biochem Biophys Res Commun 2001; 289: 961-6.

[47] Kovanci E, Rohozinski J, Simpson JL, Heard MJ, Bishop CE, Carson SA. Growth differentiating factor-9 mutations may be associated with premature ovarian failure. Fertil Steril 2007; 87: 143-6.

[48] Takebayashi K, Takakura K, Wang H, Kimura F, Kasahara K, Noda Y. Mutation analysis of the growth differentiation factor-9 and $-9 \mathrm{~B}$ genes in patients with premature ovarian failure and polycystic ovary syndrome. Fertil Steril 2000; 74: 976-9.

[49] Hanrahan JP, Gregan SM, Mulsant P, et al. Mutations in the genes for oocyte-derived growth factors GDF9 and BMP15 are associated with both increased ovulation rate and sterility in Cambridge and Belclare sheep (Ovis aries). Biol Reprod 2004; 70: 900-9

[50] Juengel JL, Hudson NL, Heath DA, et al. Growth differentiation factor 9 and bone morphogenetic protein 15 are essential for ovarian follicular development in sheep. Biol Reprod 2002; 67: 1777 89.

[51] Braw-Tal R, McNatty KP, Smith P, et al. Ovaries of ewes homozygous for the X-linked Inverdale gene (FecXI) are devoid of secondary and tertiary follicles but contain many abnormal structures. Biol Reprod 1993; 49: 895-907.

[52] Montgomery GW, McNatty KP, Davis GH. Physiology and molecular genetics of mutations that increase ovulation rate in sheep. Endocr Rev 1992; 13: 309-28.

[53] Souza CJ, MacDougall C, Campbell BK, McNeilly AS, Baird DT The Booroola $(\mathrm{FecB})$ phenotype is associated with a mutation in the bone morphogenetic receptor type 1 B (BMPR1B) gene. J Endocrinol 2001; 169: R1-6.

[54] Chand AL, Ponnampalam AP, Harris SE, Winship IM, Shelling AN. Mutational analysis of BMP15 and GDF9 as candidate genes for premature ovarian failure. Fertil Steril 2006; 86: 1009-12.

[55] Filho FLT, Baracat EC, Lee TH, et al. Aberrant expression of growth differentiation factor-9 in oocytes of women with polycystic ovary syndrome. J Clin Endocrinol Metab 2002; 87: 133744.

[56] Coulam CB, Adamson SC, Annegers JF. Incidence of premature ovarian failure. Obstet Gynecol 1986; 67: 604-6.

[57] Dixit H, Rao LK, Padmalatha V, et al. Mutational screening of the coding region of growth differentiation factor 9 gene in Indian women with ovarian failure. Menopause 2005; 12: 749-54.

[58] Revised 2003 consensus on diagnostic criteria and long-term health risks related to polycystic ovary syndrome (PCOS). Hum Reprod 2004; 19: 41-7.

[59] Jacobs HS. Polycystic ovaries and polycystic ovary syndrome. Gynecol Endocrinol 1987; 1: 113-31

[60] Ehrmann DA, Barnes RB, Rosenfield RL, Cavaghan MK, Imperial J. Prevalence of impaired glucose tolerance and diabetes in women with polycystic ovary syndrome. Diabetes Care 1999; 22: 141-6.

[61] Zhang X, Jafari N, Barnes RB, Confino E, Milad M, Kazer RR. Studies of gene expression in human cumulus cells indicate pentraxin 3 as a possible marker for oocyte quality. Fertil Steril 2005; 83(Suppl 1): 1169-79. 